Article

\title{
The Influence of Cryogenic Mass Exchange on the Composition and Stabilization Rate of Soil Organic Matter in Cryosols of the Kolyma Lowland (North Yakutia, Russia)
}

\author{
Alexey Lupachev ${ }^{1, *}$, Evgeny Abakumov ${ }^{2}$ and Stanislav Gubin ${ }^{1}$ \\ 1 Institute of Physicochemical and Biological Problems of Soil Science, Russian Academy of Sciences, \\ Institutskaya, 2, Moscow 142290, Russia; gubin.stas@mail.ru \\ 2 Saint-Petersburg State University, Vasilyevsky Island, line 16, 29, St.-Petersburg 199178, Russia; \\ e_abakumov@mail.ru \\ * Correspondence: a.lupachev@gmail.com; Tel.: +7-929-658-61-81
}

Academic Editors: Ulrich Kamp and Jesús Martínez Frías

Received: 21 February 2017; Accepted: 5 April 2017; Published: 11 April 2017

\begin{abstract}
Soil organic matter (SOM) was studied in different types of organo-mineral material (from surface horizons and partially isolated materials-cryoturbated or buried horizons) sampled from the surface horizons, the central parts of the Cryosol profiles, and the lower active layer. We found that the humic acids (HAs) of the cryoturbated and buried horizons showed an increased degree of oxidation and an increment of alkylaromatic and protonized aromatic fraction content. In contrast, the HAs of the surface horizons showed increased values of alkylic carbon components. The content of free radicals was essentially higher in the surface layers than in the cryoturbated and buried layers. While the bulk soil organic matter composition (total organic carbon, total nitrogen, and aromatic/aliphatic values) was not essentially different between surface, cryoturbated, and buried horizons, there were essential differences in elemental composition, carbon species, and free radical content. This indicates that the degree of humification in cryoturbated and buried organo-mineral material is higher than in surface horizons and that partial isolation results in relative stabilization of such material in soil profiles.
\end{abstract}

Keywords: Cryosols; soil organic matter; cryoturbation; solifluction; humic acids; ${ }^{13} \mathrm{C}$ NMR; electron spin resonance spectroscopy

\section{Introduction}

In Cryosols, a complicated pattern of redistribution, migration, accumulation, and cryoconservation of soil organic matter (SOM) is implemented in the course of pedogenesis due to different processes of cryogenic mass exchange [1-3]. These processes disturb the paragenetic connection of soil horizons and can significantly and relatively quickly (regarding the time of soil formation) alter the structure of soil profiles. The migration and further long-term conservation of SOM occur in cryoturbated or buried fragments of the soil organic horizons in the middle parts of soil profile and lower active layer. SOM stabilization as well as possible $\mathrm{CO}_{2}$ emission from soils is of great scientific interest for its important effect on the global carbon cycle and ecosystems stability [4-6]. Permafrost thaw and degradation nowadays is the global process, which results in SOM redistribution, alteration, and mineralization [7]. Recent studies provide evidence of a high and long-term mineralization potential of Arctic SOM under increasing temperatures [8]. The possible alteration of organic matter depends on the degree of its stabilization [9], and the last one can be assessed by various indexes of elemental composition, ${ }^{13} \mathrm{C}$ NMR (carbon-13 nuclear magnetic resonance), and ESR (electron spin resonance) 
spectroscopy and other state-of-the-art methods. That is why our study was aimed to evaluate the composition and quality of the SOM of surface horizons and of the cryoturbated and buried organic material in Cryosols of the Kolyma Lowland (North Yakutia, Russia).

Long-term and widespread processes of cryogenic mass-exchange take place in the majority of permafrost-affected soils [10]. One of its typical manifestations is cryoturbation-the migration of fragments of the surface organo-mineral soil horizons into the mineral parts of a soil profile due to annual freeze-thaw cycles. This organic material begins to transform, but it is relatively stable in regimes of low temperatures, a lack of free oxygen, low microbial activity, etc. After numerous annual freeze-thaw cycles, this material can migrate downwards to the surface of permafrost and begin to accumulate there [11]. Another mechanism of migration of the organic material to the central parts of the Cryosol profiles is its burial under the influence of slope processes widespread in the cryolithozone (e.g., solifluction, suffosion, and creep). In the course of solifluction, even on gentle slopes, sloughing, partial destruction, and turnover of soil bodies take place. As a result, the material of organo-mineral horizons is overlapped by that of the lower mineral horizons. In some cases, both processes may lead to the long-term preservation of viable soil fauna-ciliates, flagellates, and nematodes [12].

Taking into account the wide geographical distribution of permafrost-affected soils, the amount of the organic material that migrates within soil profiles every year due to processes of cryogenic mass exchange and shifts in the polar environments due to global climate change, the issues of intraprofile transformation and stabilization of organic substances become increasingly challenging. In this context, an investigation of the SOM stabilization rate and humification degree became urgent, namely a qualitative assessment of SOM storages in permafrost-affected soils containing buried or partially isolated fragments of organic material. Not only is quantity (stocks, content, etc.) an important index in the evaluation of the SOM stabilization rate, but qualitative indexes-the degree of aromatization, the humification rate, and the biochemical activity-are important as well.

Thus, the objective of this study was to evaluate SOM transformation under partial isolation (cryoturbation and burying process) in permafrost-affected soils in comparison with SOM in surface organo-mineral horizons, with special reference to its molecular composition.

The specific objectives of investigation were as follows:

(1) to evaluate the bulk content and elemental composition of humic acids (HAs), extracted from surface horizons, the central parts of soil profile, and the lower active layer;

(2) to assess the molecular composition of the HAs by solid state ${ }^{13} \mathrm{C}$ NMR resonance;

(3) to evaluate the degree of HA molecule stabilization using electron spin resonance.

\section{Study Area}

The zonal automorphic soils at the Kolyma Lowland are Turbic Cryosols [10,13]. These soils develop in areas with microtopography dominated by non-sorted circles. The landcover type is tundra, and the vegetation community belongs to Subzone B, as defined by Walker et al. [14]. There were two keystone sites selected for this study: the right bank of the Khomus-Yuriakh River and the mouth of the Sukharnaya River (Figure 1). Soil-forming deposits are presented with silty loams of the Ice Complex suite on both sites [15]. Three soil profiles of raw-humus Cryosols were studied on watersheds and slopes where the patch formation, cryoturbation, and solifluction are well manifested. The mesorelief on both keysites is undulating with a small variation of relief (50-200 m). Thermokarst relief forms are widespread in this area.

At the keysite Khomus-Yuriakh, the mean annual air temperature is $-13.8^{\circ} \mathrm{C}$, the mean annual precipitation is $218 \mathrm{~mm}$ (meteorological station Chokurdakh \#21946 [16]). At the keysite Sukharnaya, the mean annual air temperature is $-12.2{ }^{\circ} \mathrm{C}$, and the mean annual precipitation is $151 \mathrm{~mm}$ (meteorological station Ambarchik \#25034 [16]). Frost boils mainly determine the ground pattern on both sites. Maximum depth of the active layer was measured by authors on both sites in the end of the thawing season (mid-September 2005 for Khomus-Yuriakh; early September 2013 for Sukharnaya). 
The average thickness of the active layer at Khomus-Yuriakh site is $50.3 \mathrm{~cm}(n=30)$ : Under the center of the circle, it is $68 \mathrm{~cm}$; under the inter-circle, $28 \mathrm{~cm}$; under sedge-grass hillocks, $55 \mathrm{~cm}$. The average thickness of the active layer at Sukharnaya site is $49.3 \mathrm{~cm}(n=40)$ : Under the center of the circle, it is 61 $\mathrm{cm}$; under the inter-circle, $42 \mathrm{~cm}$; under sedge-grass hillocks, $45 \mathrm{~cm}$.

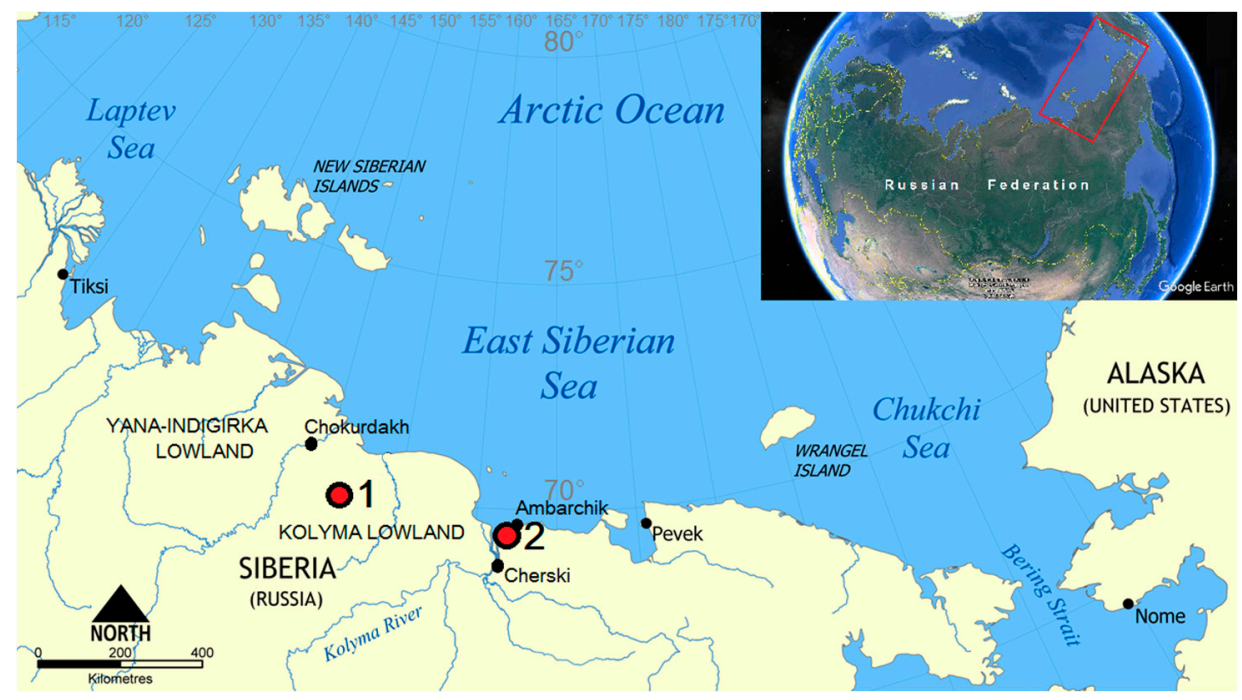

Figure 1. Keysites of the Kolyma Lowland. 1: Khomus-Yuriakh; 2: Sukharnaya.

\section{Materials and Methods}

\subsection{Routine Soil Analyses and Microscopy}

Six soil samples were analyzed from different genetic horizons enriched with organic material of zones and layers in the Cryosol profiles (Table 1, Figure 2). Taking into account the genesis of the material studied, the samples were taken from surface organo-mineral horizons (Samples 1 and 3); organo-mineral layers (fragments of the former surface horizons) buried in the development of solifluction processes (Sample 4); zones of cryoturbated organic material in the central part of the profile (Sample 5); zones of cryoturbated organic material in the lower active layer (Samples 2 and 6).

Table 1. Physico-chemical properties of organo-mineral material from different parts of Cryosol profiles.

\begin{tabular}{|c|c|c|c|c|c|c|c|c|}
\hline $\begin{array}{l}\text { Sample } \\
\text { Code }\end{array}$ & $\begin{array}{c}\text { Loss on } \\
\text { Ignition } \\
(\%)\end{array}$ & $\begin{array}{c}\text { Total C } \\
(\%)\end{array}$ & $\begin{array}{c}\text { Total N } \\
(\%)\end{array}$ & $\mathrm{C} / \mathbf{N}$ & $\mathrm{pH}$ & $\begin{array}{l}\text { Color (by } \\
\text { Munsell } \\
\text { System) }\end{array}$ & $\begin{array}{l}\text { Radiocarbon } \\
\text { Ages (yr BP) }\end{array}$ & $\begin{array}{c}\text { Calibrated Ages } \\
1 \sigma(\mathrm{yr} \text { BP) }\end{array}$ \\
\hline 2 & 14.75 & 6.64 & 0.36 & 18.54 & 5.60 & 5YR 3/2 & $1900 \pm 40$ & 1813-1897 \\
\hline 3 & 12.43 & 1.64 & 0.15 & 10.74 & 5.93 & 7.5YR 4/2 & $\mathrm{n} / \mathrm{a}$ (modern) & $\mathrm{n} / \mathrm{a}$ \\
\hline 4 & 14.67 & 1.42 & 0.13 & 10.64 & 6.78 & $7.5 Y R 3 / 2$ & $2370 \pm 50$ & $2299-2351$ \\
\hline 6 & 15.24 & 5.58 & 0.35 & 15.72 & 6.10 & 10YR 6/1 & $1530 \pm 50$ & 1461-1513 \\
\hline
\end{tabular}

n/a: not available.

All chemical soil parameters were studied on a fine earth of soil after being passed through a $2 \mathrm{~mm}$ sieve. Total organic carbon and nitrogen content were determined with use of $\mathrm{C}-\mathrm{H}-\mathrm{N}$ analyzer (Euro EA3028-HT, Eurovector, Redavalle, Italy). The procedure was based on the oxidation of organic matter in the presence of oxygen and on further determination of carbon, nitrogen, and hydrogen using gas chromatography. The oxygen content was calculated by the difference between the mass of organic material, $\mathrm{C}, \mathrm{H}$, and $\mathrm{N}$ and ash content. The $\mathrm{pH}$ values have been determined in 1:2.5 soil/water suspension. 
Thin sections from sampled soil material were prepared using a Canadian balm and analyzed with an optical microscope (Axioscope A1, Carl Zeiss, Oberkochen, Germany), and images were taken with a Axiocam MR5 camera (Carl Zeiss); the submicrostructure of the soils was investigated using a Vega 3 LMU electron microscope (Tescan, Brno, Czech Republic).

Radiocarbon dating was carried out on plant macroremains in the Radiocarbon Laboratory, Institute of Geography, Russian Academy of Sciences (Sample 2), and in the Kyiv Radiocarbon Laboratory, Institute of Environmental Geochemistry, National Academy of Sciences of Ukraine (Samples 4-6). Calibrations were performed using the Calib 7.1 software [17].

\subsection{Extraction of Humic Acids}

HAs were extracted from each soil sample according to the following procedure [18]. Briefly, HAs were extracted with $0.1 \mathrm{M} \mathrm{NaOH}$ (soil/solution ratio 1:10) under nitrogen gas. After $24 \mathrm{~h}$ of shaking, the alkaline supernatant was separated from the soil residue by centrifugation at $1516 \times g$ for $20 \mathrm{~min}$ and acidified to $\mathrm{pH} 1$ with $6 \mathrm{M} \mathrm{HCl}$ to induce the precipitation of HAs. The supernatant, which contained fulvic acids (FAs), was separated from the precipitate (HAs) by centrifugation at $1516 \times g$ for $15 \mathrm{~min}$. The HAs were then redissolved in $0.1 \mathrm{M} \mathrm{NaOH}$ and shaken for $4 \mathrm{~h}$ under $\mathrm{N}_{2}$ before the suspended solids were removed by centrifugation. The HA solution was acidified again with $6 \mathrm{M} \mathrm{HCl}$ to $\mathrm{pH} 1$, and the HAs were separated by centrifugation. The HAs were demineralized via shaking overnight in $0.1 \mathrm{M} \mathrm{HCl} / 0.3 \mathrm{M} \mathrm{HF}$ (solid/solution ratio 1:1) and then repeatedly washed with deionized water until $\mathrm{pH} 3$ was reached; they were then freeze-dried [18,19].

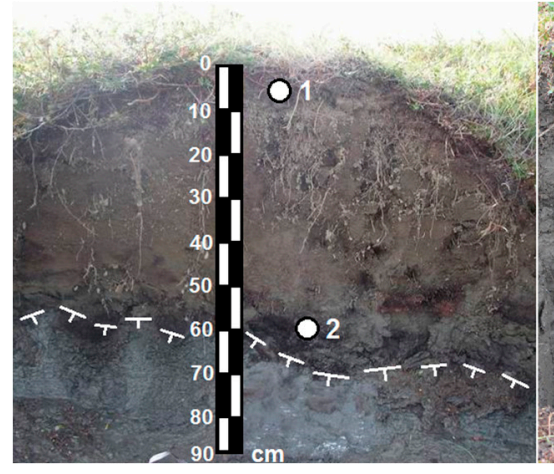

(a)

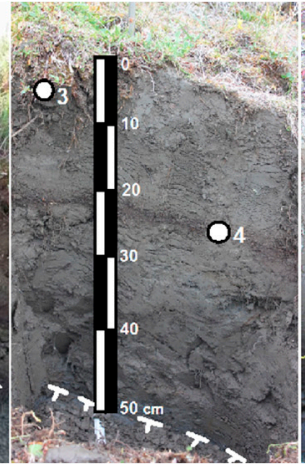

(b)

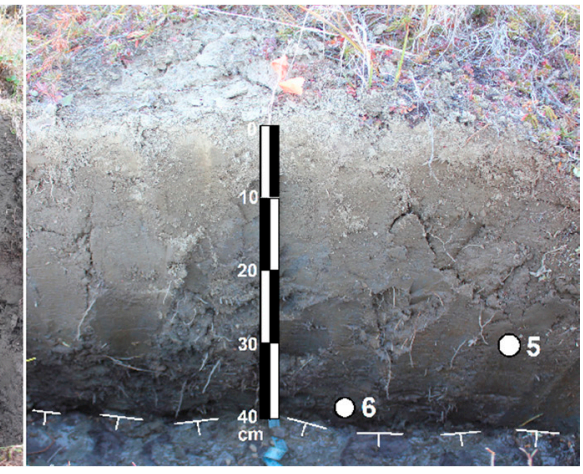

(c)

Figure 2. Soil profiles and sampling location in Turbic Cryosols of the Kolyma Lowland. (a) the Khomus-Yuriakh keysite; $(\mathbf{b}, \mathbf{c})$ the Sukharnaya keysite.

\subsection{Characterization of $H A s$}

HAs were characterized for their elemental composition (C, N, and H) using a Euro EA3028-HT (Eurovector) analyzer. Data were corrected for water and ash content. Oxygen content was calculated by the difference, taking the ash content into account. The elemental ratios reported in this paper are based on weight. HAs were characterized for their elemental composition $(\mathrm{C}, \mathrm{N}, \mathrm{H}$, and $\mathrm{S})$ using a $\mathrm{CHN}$ 185B-Hewlett Packard analyzer (Hewlett Packard, Palo Alto, CA, USA). Data were corrected for water and ash content. Oxygen content was calculated by the difference. Investigations were carried out with a NMR spectrometer Bruker Avance III WB 400 (Bruker, Billerica, MA, USA) (100.64 MHz for ${ }^{13} \mathrm{C}$ and $400.23 \mathrm{MHz}$ for ${ }^{1} \mathrm{H}$ ). Solid-phase samples were placed in a $4 \mathrm{~mm}$ zirconium oxide rotor and spun at a frequency of $12.5 \mathrm{kHz}$ at the magic angle; for the registration of ${ }^{13} \mathrm{C}$ spectra, the cross-polarization sequence of excitation pulses was used (Cross-Polarization Magic Angle Spinning). The contact time was $2 \mathrm{~ms}$; the delay time, $1 \mathrm{~s}$; the number of scans, 50,000.

Groups of structural compounds were identified by the following chemical shifts values: 200-185 ppm—carboxyl group and amidic carbonyl; 185-160 ppm—aromatic C of fenols and phenol 
esters; 160-140 ppm—alkylaromatic; $140-110$ ppm — protonize aromatic carbon and bridgehead C; 110-95 ppm—cellulose anomeric carbon and hemiacetal carbon; 95-60 ppm-resonance region of $\mathrm{C}-\mathrm{H}$ bonds, secondary alcohols, and other carbon atoms bound to oxygen; $60-45 \mathrm{ppm}$-methyl group resonance region of aliphatic and aromatic ethyl ethers, amino acid carbons, and methyl esters of carboxylic groups; 45-32 ppm-resonance region of quaternary carbon and $\mathrm{CH}$ carbons; 32-27 ppm-resonance region of $\mathrm{CH}_{2}$ alkyl structures in transconformation; 27-10 ppm-resonance region of alkyl methyls and $\mathrm{CH}_{2}$ units [20-24].

The aromatic fraction content was assessed by summing 100-170 + 183-190 ppm areas, and aliphatic carbon content was summarized at aliphatic 0-100 + 164-183 ppm [25,26].

The ESR spectra were recorded on a JES FA 300 spectrometer (JEOL, Tokyo, Japan) in X-diapason with a free-radical modulation amplitude of $0.06 \mathrm{mT}$ and a microwave power in the cavity of $1 \mathrm{~mW}$. Magnesium powder with fixed radical concentration was used as an external standard. The concentration of paramagnetic centers in powders was determined by comparison of relative signal intensities of the external standard and measured sample with the use of the program JES-FA swESR v. 3.0.0.1 (JEOL).

\subsection{Statistics}

A one-way analysis of variance (ANOVA, Statistica Base 12.6, Dell, Round Rock, TX, USA) was carried out in order to identify relationships between the obtained data on the composition of HAs and the type of soil horizons (surface or partially isolated organo-mineral layers-cryoturbated or buried). This method is based on an estimation of the significance of average differences between three or more independent groups of data combined by one feature (factor). The null hypothesis of the average equality was tested during analysis, suggesting provisions on the equality or inequality of variances. In case of rejection of the variance's equality hypothesis, basic analysis is not applicable. If the variances are equal, the F-test Fisher criterion is used for evaluation of intergroup and intragroup variability. If F-statistics exceeds the critical value, the null hypothesis is rejected considering inequality of averages.

\section{Results and Discussion}

\subsection{Genesis, Structure, and Morphology of Organo-Mineral Material}

4.1.1. Modern Surface Organic and Organo-Mineral Horizons Undisturbed by Frost Boiling (Samples 1 and 3)

The surface organo-mineral horizon characteristic of the soils at the keysites is a combination of two genetically connected horizons (Figure 3a): the upper litter-peat horizon, which is nonuniform in botanical composition and friable (abundant medium and large pores and voids in $50-70 \%$ of the area), with weakly decomposed organic residues (almost without inclusion of mineral material), acid, and a loss in ignition of $20-35 \%$. This horizon is underlain by a thin (sometimes discrete) raw-humus horizon, which is composed of organo-mineral material with partially decomposed organic residues, aggregated, weakly compacted (abundant very fine and fine pores and voids in 30-50\% of the total area), and weakly acidic, with a loss of ignition of $8-35 \%$. 


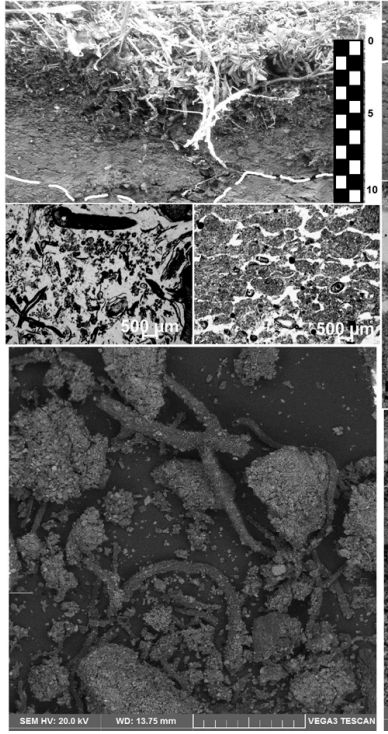

(a)

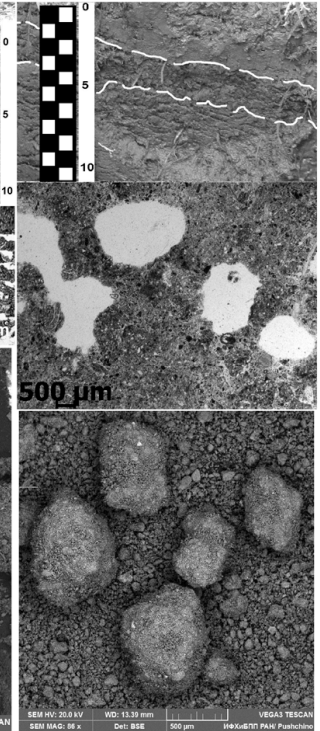

(b)

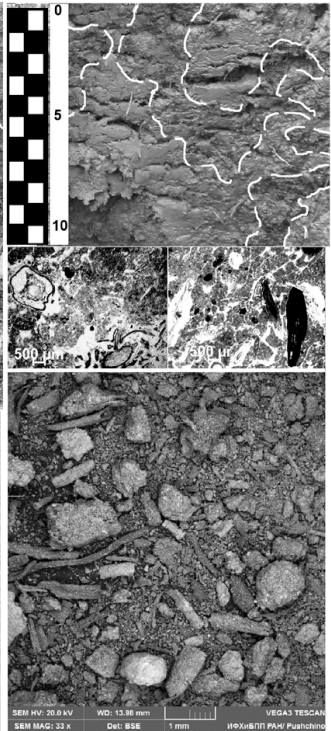

(c)

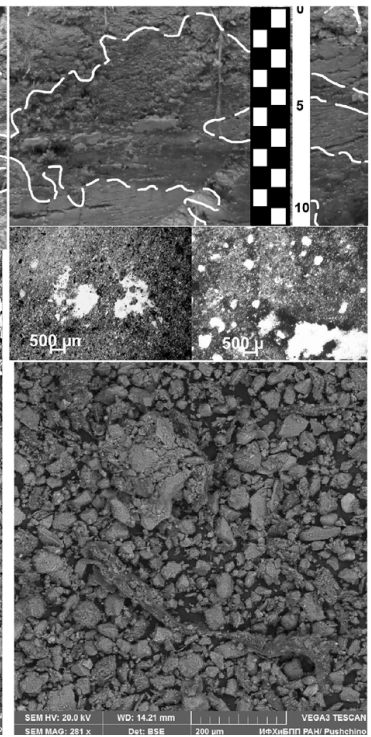

(d)

Figure 3. Organo-mineral material from different parts of Turbic Cryosol profiles (upper image: general view of the soil pit; middle: the thin section; lower: electron microscopy). (a) Surface organo-mineral horizons. (b) Former surface organo-mineral horizons buried after solifluction processes; (c) Cryoturbated organo-mineral material in the central parts of the profiles; (d) Cryoturbated organo-mineral material accumulated in the suprapermafrost horizons of Cryosols.

4.1.2. Fragments of Former Surface Organo-Mineral Horizons Buried after Solifluction Processes (Sample 4)

On the slopes affected by solifluction, a new soil profile is formed over the former one, and its mineral part contains an interlayer of the buried organic material-a former surface soil horizon (Figure 3b). The latter is smooth, uniform in its properties, and stable by the position in the nanopolygon material. In the enclosing mineral material, the buried fragments of the surface organo-mineral soil horizons are distinguished by their linear expansion (from tens of $\mathrm{cm}$ ), and in some zones, the material preserves its surface organization (structure, root orientation, changes in color with depth, etc.); it is compacted (it has fine and very fine pores and voids in about $20 \%$ of the area) and pierced with plant roots.

\subsubsection{Fragments of Cryoturbated Organo-Mineral Material in the Central Parts of Cryosol Profiles (Sample 5)}

Due to the seasonal thawing-freezing cycles and the drastic differences in the mechanical and thermophysical properties of its raw organic material and mineral soil, a complicated swirl (vortex) pattern of cryoturbation in the soil profile is formed (Figure 3c). The material of the zones rich in organic matter is distinguished by a darker color in the upper and central parts of the soil profiles; the boundaries between these zones and the mineral mass containing zones are clear. The shape of the patches and mottles is often elongated; the soil is compacted (abundant very fine and fine pores and voids; their area is 20-30\%) and structureless, with weakly decomposed plant residues.

4.1.4. Fragments of Cryoturbated Organo-Mineral Material Accumulated in the Lower Active Layer (Samples 2 and 6)

During thawing, the redistribution of raw organic material continues; it is destroyed and gradually mixed with the mineral material of the central and lower parts of the active layer. Down the profiles, the material of the zones is gradually transformed into dark zones consisting of a mixture of mineral and well-decomposed organic masses (Figure 3d). The cryoturbated organo-mineral material in the 
lower active layer is better mixed with the enclosing mineral mass. The boundaries between the zones are indistinct; the material of the zones is compact (fine and very fine pores and voids are moderately spread, and their area is $20 \%$ ), structureless, and excessively moistened, and water often trickles. In the short period of time during the summer season, the lower active layer is thawed (not more than 2 weeks in a year), and temperatures close to $0{ }^{\circ} \mathrm{C}$ in this period promote the preservation of organic matter.

\subsection{Total Organic Carbon and Nitrogen Content}

The total organic carbon content (Table 1) in the studied soils was typical for soils of cold polar environments, while the nitrogen content increased in comparison with previously published work for the Lena river delta, where the $\mathrm{C} / \mathrm{N}$ ratio is more than 20 [2]. Relatively low $\mathrm{C} / \mathrm{N}$ ratio values indicate that the SOM in the investigated soils is more or less transformed in comparison with histic material of the uppermost Cryosol horizons with abundant moss peat fragments and plant litter. The data obtained coincides with those published earlier [26,27]. The extraction yield of the HA preparations was not high $-0.2 \%-1.0 \%$ - which indicates the alteration degree of organic matter due to low humification.

\subsection{Elemental Composition of HAs}

In general, elemental composition of the HAs is comparable with previously reported data for soils of polar environments [25-27]. The characteristic features of HAs, formed in cold environments and especially in permafrost-affected soils, are the relatively increased $\mathrm{H}$ content and the decreased portion of $\mathrm{O}$ in comparison with soils of boreal and subboreal environments [25], which is evident both from the bulk element content and the $\mathrm{H} / \mathrm{C}$ and $\mathrm{O} / \mathrm{C}$ ratios (Table 2). Remarkably, the O/C ratio increased in the organic matter buried by solifluction (Sample 4) compared with Sample 3-the surface organo-mineral horizon. No alteration in the $\mathrm{C} / \mathrm{N}$ ratio of the HAs was fixed for the surface, cryoturbated, or buried horizons. This indicates that only some intensification of the accumulation of oxygen-containing groups occurs due to the isolation of organic matter in cryoturbated and buried horizons. This could be an illustration of more pronounced humification in conditions of organic material isolation.

Table 2. Elemental composition (\% to ashless dry material) and atomic ratios in humic acids (HAs).

\begin{tabular}{cccccccc}
\hline Sample Code & $\mathbf{C}$ & $\mathbf{H}$ & $\mathbf{N}$ & $\mathbf{O}$ & $\mathbf{C} / \mathbf{N}$ & $\mathbf{H} / \mathbf{C}$ & $\mathbf{O} / \mathbf{C}$ \\
\hline 1 & 47.20 & 5.71 & 4.25 & 43.01 & 10.97 & 0.12 & 0.91 \\
2 & 46.17 & 5.52 & 3.48 & 44.99 & 13.12 & 0.12 & 0.98 \\
3 & 46.82 & 5.29 & 4.04 & 44.02 & 11.46 & 0.11 & 0.94 \\
4 & 36.08 & 4.36 & 3.27 & 56.37 & 10.92 & 0.12 & 1.57 \\
5 & 48.26 & 4.29 & 3.93 & 43.7 & 12.14 & 0.09 & 0.91 \\
6 & 48.24 & 5.59 & 3.52 & 42.83 & 13.56 & 0.12 & 0.89 \\
\hline
\end{tabular}

\subsection{Structural Composition of the HAs}

Representative ${ }^{13} \mathrm{C}$ NMR spectra are given in Figure 4, and the results of its interpretation are presented in Tables 3 and 4. Comparing surface, cryoturbated, and buried horizons, we can see that there is an essential increase in alkylaromatic (160-140 ppm) and protonized (140-110 ppm) aromatic carbon in the lower active layer. In addition, there is a simultaneous increment in carboxylic groups (185-200 ppm), which corresponds well with the increasing degree of oxidation of those HAs, which is evident from the results of elemental analyses. The content values of alkylic and methyls groups (0-27 ppm) and of aliphatic and aromatic ethyl ethers, amino acid carbons, and methyl esters (40-60 ppm) were higher in the topsoil material than in the cryoturbated and buried material. Nevertheless, the bulk component composition of HAs is not different in the investigated samples. Only a sharp increase in the aromatic part was pronounced in Sample 5. An increase in the 
humification rate accompanied by a decrease in alkylic carbon content and an increment in aromatic compounds is evident.

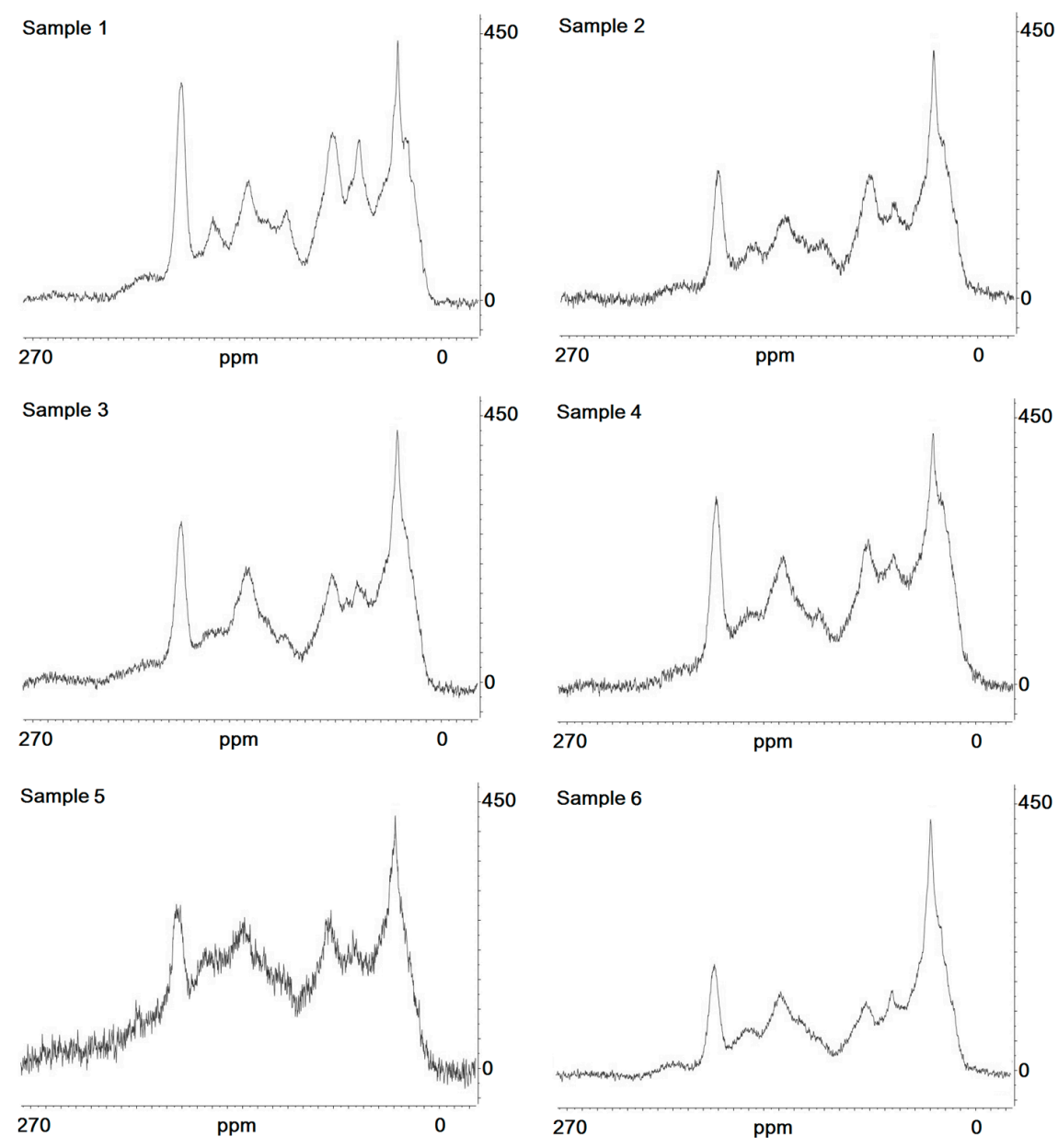

Figure $4 .{ }^{13} \mathrm{C}$ NMR spectra of studied samples; $x$-axis: chemical shift (ppm); $y$-axis: intensity of signal.

Table 3. Elemental composition ( $\%$ to ashless dry material) and atomic ratios in HAs.

\begin{tabular}{ccccccccccc}
\hline \multirow{2}{*}{ Sample Code } & \multicolumn{10}{c}{ Chemical Shift (ppm) } \\
\cline { 2 - 12 } & $\mathbf{0 - 2 7}$ & $\mathbf{2 7 - 3 2}$ & $\mathbf{3 2 - 4 5}$ & $\mathbf{4 5 - 6 0}$ & $\mathbf{6 0 - 9 5}$ & $\mathbf{9 5 - 1 1 0}$ & $\mathbf{1 1 0 - 1 4 0}$ & $\mathbf{1 4 0 - 1 6 0}$ & $\mathbf{1 6 0 - 1 8 5}$ & $\mathbf{1 8 5}-\mathbf{2 0 0}$ \\
\hline 1 & 9.59 & 9.72 & 4.78 & 13.07 & 4.01 & 13.86 & 4.41 & 10.50 & 5.80 & 17.22 \\
2 & 7.59 & 6.60 & 5.49 & 12.26 & 3.72 & 13.73 & 13.41 & 12.47 & 6.36 & 19.33 \\
3 & 8.92 & 7.97 & 6.32 & 15.10 & 3,05 & 12.28 & 12.62 & 12.66 & 6.99 & 14.05 \\
4 & 8.09 & 8.44 & 6.06 & 14.70 & 3.18 & 13.25 & 13.59 & 13.63 & 4.13 & 14.93 \\
5 & 8.55 & 9.82 & 8.86 & 16.34 & 4.49 & 14.63 & 11.79 & 12.79 & 3.20 & 9.49 \\
6 & 6.45 & 7.20 & 5.58 & 14.78 & 2.69 & 10.27 & 11.18 & 14.74 & 8.02 & 19.03 \\
$p$ One-way ANOVA & $<0.04$ & $<0.04$ & $<0.04$ & $<0.05$ & $<0.05$ & $<0.08$ & $<0.03$ & $<0.05$ & $<0.05$ & $<0.07$ \\
\hline
\end{tabular}

Table 4. Content of aromatic and aliphatic fraction in HAs.

\begin{tabular}{ccc}
\hline Sample Code & Aromatic (\%) & Aliphatic (\%) \\
\hline 1 & 27.24 & 72.76 \\
2 & 25.76 & 74.24 \\
3 & 28.25 & 71.75 \\
4 & 27.85 & 72.14 \\
5 & 34.62 & 65.37 \\
6 & 26.57 & 73.42 \\
\hline
\end{tabular}




\subsection{Biochemical Activity of the HAs: Insights from Spectroscopy of Electron Spin Resonance}

A typical ESR spectrum of HAs investigated is presented on Figure 5, and the ESR parameters are similar to the HAs and FAs of temperate soils [28,29]. The spectrum shows a single wide line with a $\mathrm{g}$-factor ranging from 1.98890 to 1.99999 , which is attributed to the presence of stable semiquinone free radicals in the HA macromolecules (Table 5). The free radical content was essentially higher in the surface horizons than that in the isolated horizons. This corresponds well with previous data $[27,30]$ that shows that the isolation of buried organic matter in the lower active layer results in a decline in free radical content. This indicates, firstly, the increased biochemical activity of HAs and, secondly, a low degree of SOM stabilization. Both these indexes can be interpreted as a result of the prevalence of fresh undecomposed organic material in the surface horizons. In contrast, in the cryoturbated and buried organic material, which is partially isolated from the topsoil, there is essentially less free radical content. This illustrates the higher stage of stabilization of HAs in buried horizons and cryoturbated and buried fragments of organic material.

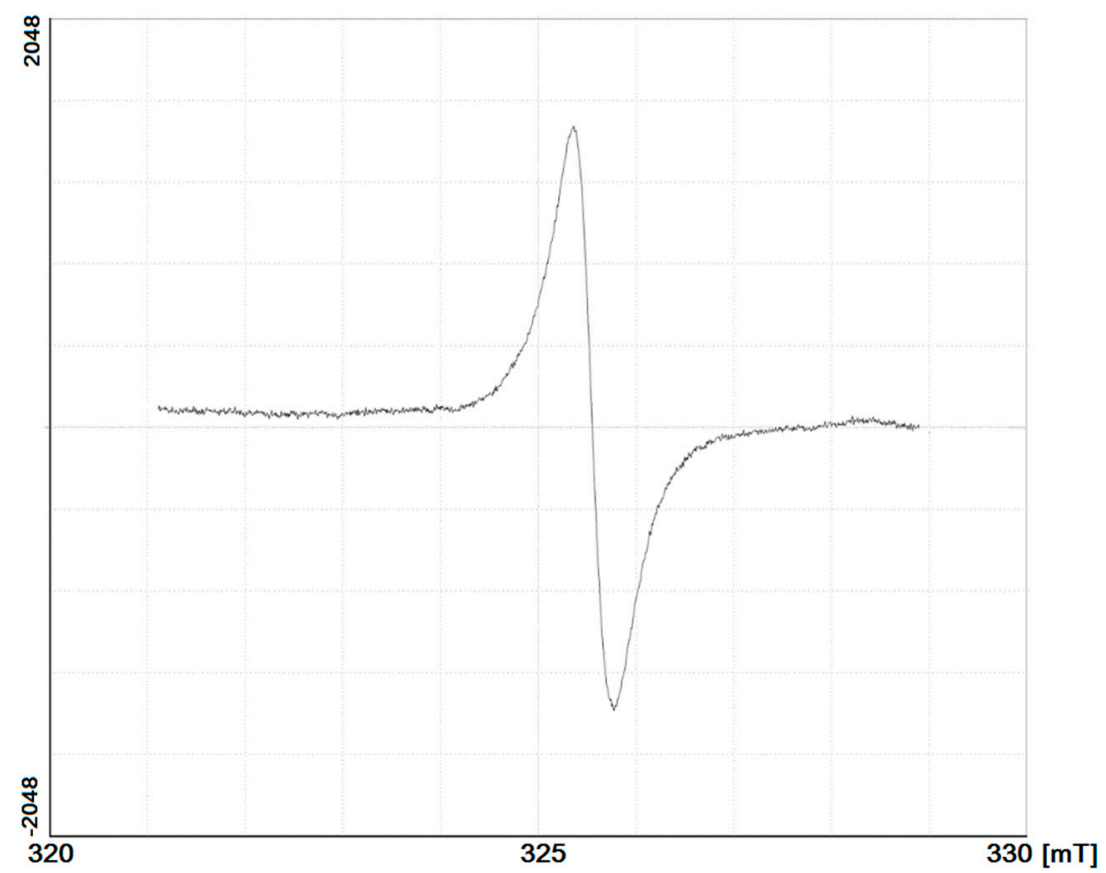

Figure 5. Typical electron spin resonance spectrum of investigated HAs.

Table 5. Free radical content in the HAs.

\begin{tabular}{ccc}
\hline Sample Code & Mass Concentration of Free Radical, $\mathbf{1 0}^{\mathbf{1 5}} \mathbf{s p i n \cdot \mathbf { g } ^ { \mathbf { - 1 } }}$ & g-Factor \\
\hline 1 & $1.206 \times 10^{15}$ & 1.98888 \\
2 & $4.496 \times 10^{14}$ & 1.98887 \\
3 & $2.090 \times 10^{15}$ & 1.98863 \\
4 & $9.307 \times 10^{14}$ & 1.98860 \\
5 & $5.23 \times 10^{14}$ & 1.98860 \\
6 & $1.059 \times 10^{14}$ & 1.98866 \\
\hline
\end{tabular}

\section{Conclusions}

Studying the surface horizons and partially isolated (cryoturbated or buried) organo-mineral material of selected Cryosols brought into light a number of significant differences in SOM content and HA elemental and structural composition in different hydrothermic conditions of the surface, central, and lowermost parts of Cryosol profiles. 
There is no essential alteration in gravimetric concentration of total organic carbon and nitrogen in HAs due to the cryoturbation or burying of SOM in the middle and lower parts of the active layer. At the same time, HAs of cryoturbated and buried horizons showed an increased degree of oxidation and an increment of alcylaromatic and protonized aromatic fraction content. In contrast, the HAs of the surface horizons showed increased values of alkylic carbon components.

The content of free radicals was essentially higher in surface horizons than in the cryoturbated and buried horizons. This corresponds with increased portions of alcylaromatic and protonized aromatic structures and indicates that the degree of HA molecule stabilization is higher in cryoturbated and buried horizons than in the surface horizons.

Finally, we can conclude that, while the bulk soil organic matter composition (total organic carbon, total nitrogen and aromatic/aliphatic values) were not essentially different between the surface and cryoturbated or buried horizons, there were essential differences in elemental composition, carbon species, and free radical content. This indicates that the degree of humification in buried organo-mineral material is higher than in surface material and that partial isolation of such material in the lower active layer results in its relative stabilization in soil profiles.

Acknowledgments: This work was partially supported by the Russian Foundation for Basic Research, projects 15-04-03960, 16-34-60010. Analyses were carried out at the Centre for Magnetic Resonance and at the Centre for Chemical Analysis and Materials Research of Research Park of St. Petersburg State University. The microstructure in thin sections and the submicrostructure of the soils were studied in the Chemical-Analytical Complex of the Institute of Physicochemical and Biological Problems of Soil Sciences, Russian Academy of Sciences in Pushchino.

Author Contributions: Alexey Lupachev and Stanislav Gubin performed the expedition with fieldwork and soil sampling; Evgeny Abakumov analyzed the composition of SOM and contributed analysis tools; Alexey Lupachev and Evgeny Abakumov wrote the paper.

Conflicts of Interest: The authors declare no conflict of interest. The funding sponsors had no role in the design of the study; in the collection, analyses, or interpretation of data; in the writing of the manuscript; or in the decision to publish the results.

\section{References}

1. Schädel, C.; Schuur, E.A.G.; Bracho, R.; Elberling, B.; Knoblauch, C.; Lee, H.; Luo, Y.; Shaver, G.R.; Turetsky, M.R. Circumpolar assessment of permafrost $C$ quality and its vulnerability over time using long-term incubation data. Glob. Chang. Biol. 2014, 20, 641-652. [CrossRef] [PubMed]

2. Zubrzycki, S.; Kutzbach, L.; Pfeiffer, E.-M. Permafrost affected soils and their carbon pools with a focus on the Russian Arctic. Solid Earth 2014, 5, 595-609. [CrossRef]

3. Schuur, E.A.G.; McGuire, A.D.; Grosse, G.; Harden, J.W.; Hayes, D.J.; Hugelius, G.; Koven, C.D.; Kuhry, P. Climate change and the permafrost carbon feedback. Nature 2015, 520, 171-179. [CrossRef] [PubMed]

4. Roulet, N.T. Peatlands, carbon storage, greenhouse gases and the Kyoto protocol: Prospects and significance for Canada. Wetlands 2000, 20, 605-615. [CrossRef]

5. Zamolodchikov, D.G.; Utkin, A.I.; Korovin, G.N.; Chestnykh, O.V. Dynamics of carbon pools and fluxes in Russia's forest lands. Russ. J. Ecol. 2005, 36, 291-301. [CrossRef]

6. Schädel, C.; Bader, M.K.-F.; Schuur, E.A.G.; Biasi, C.; Bracho, R.; Čapek, P.; De Baets, S.; Diáková, K.; Ernakovich, J.; Estop-Aragones, C. Potential carbon emissions dominated by carbon dioxide from thawed permafrost soils. Nat. Clim. Chang. 2016, 6, 950-953. [CrossRef]

7. Tarnocai, C.; Canadell, J.G.; Schuur, E.A.G.; Kuhry, P.; Mazhitova, G.; Zimov, S. Soil organic carbon pools in the northern circumpolar permafrost region. Glob. Biogeochem. 2009, 23, 1-11. [CrossRef]

8. Elberling, B.; Michelsen, A.; Schädel, C.; Schuur, E.A.G.; Christiansen, H.H.; Berg, L.; Tamstorf, M.P.; Sigsgaard, C. Long-term $\mathrm{CO}_{2}$ production following permafrost thaw. Nat. Clim. Chang. 2013, 3, 890-894. [CrossRef]

9. Dai, X.Y.; Ping, C.L.; Michaelson, G.J. Characterizing soil organic matter in Arctic tundra soils by different analytical approaches. Org. Geochem. 2002, 33, 407-419. [CrossRef]

10. Bockheim, J.G.; Tarnocai, C. Recognition of cryoturbation for classifying permafrost-affected soil. Geoderma 1998, 81, 281-293. [CrossRef] 
11. Lupachev, A.V.; Gubin, S.V. Suprapermafrost organic-accumulative horizons in the tundra Cryozems of Northern Yakutia. Eurasian Soil Sci. 2012, 45, 45-55. [CrossRef]

12. Gubin, S.V.; Lupachev, A.V.; Shatilovich, A.V.; Mylnikov, A.P.; Ryss, A.Y.; Veremeeva, A.A. The influence of cryogenic mass exchange on the distribution of viable microfauna in Cryozems. Eurasian Soil Sci. 2016, 49, 1400-1413. [CrossRef]

13. IUSS Working Group WRB. World Reference Base for Soil Resources 2014. In International Soil Classification System for Naming Soils and Creating Legends for Soil Maps; World Soil Resources Reports No. 106; Food and Agriculture Organization (FAO): Rome, Italy, 2014.

14. Walker, D.A.; Raynolds, M.K.; Daniëls, F.J.A.; Einarsson, E.; Elvebakk, A.; Gould, W.A.; Katenin, A.E.; Kholod, S.S.; Markon, C.J.; Melnikov, E.S.; et al. The Circumpolar Arctic vegetation map. J. Veg. Sci. 2005, 16, 267-282. [CrossRef]

15. Murton, J.B.; Goslar, T.; Edwards, M.E.; Bateman, M.D.; Danilov, P.P.; Savvinov, G.N.; Gubin, S.V.; Ghaleb, B.; Haile, J.; Kanevskiy, M.; et al. Wolfe Palaeoenvironmental Interpretation of Yedoma Silt (Ice Complex) Deposition as Cold-Climate Loess, Duvanny Yar, Northeast Siberia. Permafr. Periglac. Process. 2015, 26, 208-288. [CrossRef]

16. Russian Institute of Hydrometeorological Information-World Data Center. Available online: http://meteo. ru/english/index.php (accessed on 15 February 2017).

17. Stuiver, M.; Reimer, P.J.; Reimer, R.W. CALIB 7.1. 2017. Available online: http:/ / calib.org (accessed on 15 February 2017).

18. Schnitzer, M. Organic matter characterization. In Methods of Soil Analysis; Page, B., Miller, R., Keeney, D., Eds.; Soil Science Society of America: Madison, WI, USA, 1982; pp. 581-594.

19. Schnitzer, M. Soil organic matter-The next 75 years. Soil Sci. 1991, 151, 41-58. [CrossRef]

20. Dai, X.Y.; Ping, C.L.; Candler, R.; Haumaier, L.; Zech, W. Characterization of soil organic matter fractions of tundra soils in arctic Alaska by Carbon-13 nuclear magnetic resonance spectroscopy. Soil Sci. Soc. Am. J. 2001, 65, 87-93. [CrossRef]

21. Chefetz, B.; Simpson, M.J.; Deshmukh, A.P.; Hatcher, P.G. Structural components of humic acids as determined by chemical modifications and carbon-13 NMR, pyrolysis- and thermochemolysis-gas chromatography/mass spectrometry. Soil Sci. Soc. Am. J. 2002, 66, 1159-1171. [CrossRef]

22. Frund, R.; Guggenberger, G.; Haider, K. Recent advances in the spectroscopic characterization of soil humic substances and their ecological relevance. Pflanzenernahr. Bodenkd. 1994, 157, 175-186. [CrossRef]

23. Gonzalez-Perez, M.; Martin-Neto, L.; Saab, S.C.; Novotny, E.H.; Milori, D.M.B.P.; Bagnato, V.S.; Colnago, L.A.; Melo, W.J.; Knicker, H. Characterization of humic acids from a Brazilian Oxisol under different tillage systems by EPR, ${ }^{13} \mathrm{C}$ NMR, FTIR and fluorescence spectroscopy. Geoderma 2004, 118, 181-190. [CrossRef]

24. Chukov, S.N.; Abakumov, E.V.; Tomashunas, V.M. Characterisation of humic acids isolated from Antarctic soils by ${ }^{13}$ C NMR spectroscopy. Eurasian Soil Sci. 2015, 48, 1207-1211. [CrossRef]

25. Lodygin, E.D.; Beznosikov, V.A.; Vasilevich, R.S. Molecular composition of humic substances in tundra soils ( ${ }^{13}$ C-NMR spectroscopic study). Eurasian Soil Sci. 2014, 47, 400-406. [CrossRef]

26. Ejarque, E.; Abakumov, E. Stability and biodegradability of organic matter from Arctic soils of Western Siberia: insights from ${ }^{13}$ C-NMR spectroscopy and elemental analysis. Solid Earth 2016, 7, 153-165. [CrossRef]

27. Abakumov, E.V.; Tomashunas, V.M. ${ }^{13} \mathrm{C}$ NMR and ESR characterization of humic substances isolated from soils of two Siberian arctic islands. Int. J. Ecol. 2015, 1-7. [CrossRef]

28. Senesi, N.; D'Orazio, V.; Ricca, G. Humic acids in the first generation of EUROSOILS. Geoderma 2003, 116, 325-344. [CrossRef]

29. Senesi, N. Molecular and quantitative aspects of the chemistry of fulvic acids and its interactions with mineral ions and organic chemicals. Anal. Chim. Acta 1990, 232, 51-75. [CrossRef]

30. Chukov, S.; Ejarque, E.; Abakumov, E. Characterisation of the humic acids of soils of tundra zone by electron spin resonance spectroscopy. Eurasian Soil Sci. 2017, 50, 35-39. [CrossRef]

(C) 2017 by the authors. Licensee MDPI, Basel, Switzerland. This article is an open access article distributed under the terms and conditions of the Creative Commons Attribution (CC BY) license (http:/ / creativecommons.org/licenses/by/4.0/). 